\section{Fertility assessment in thalassemic men}

\author{
Shahla Ansari, ${ }^{1}$ Azadeh Kiumarsi, ${ }^{1}$ \\ Azita Azarkeivan, ${ }^{2}$ \\ Mohammad Mahdi Allameh, ${ }^{3}$ \\ Davood Amir kashani, ${ }^{3}$ \\ Maryam Razaghi Azar ${ }^{3}$ \\ ${ }^{1}$ Department of Pediatric Hematology, \\ StAliasghar Hospital, Iran Medical \\ University, Tehran; ${ }^{2}$ Department of \\ Thalassemia Clinic, High Institute for \\ Research and Education in Transfusion \\ Medicine, Iranian Blood Transfusion \\ Organization, Tehran; ${ }^{3}$ Department of \\ Pediatric Endocrinology, StAliasghar \\ Hospital, Iran Medical University, \\ Tehran, Iran
}

\section{Abstract \\ Male infertility in $\beta$-thalassemia} patients is typically considered to be the consequence of iron deposition in the endocrine glands. Adult male patients with $\beta$-thalassemia, on regular blood transfusions, are prone to developing acquired hypogonadism. The aim of this study was to evaluate the fertility indicators in male patients with $\beta$-thalassemia major and intermedia. In this study we evaluated testicular volume, semen parameters and serum FSH, $\mathrm{LH}$, and Testosterone concentrations in 62 male patients in reproductive age, with major and intermedia thalassemia, at a tertiary care hospital in Tehran, Iran. The range of serum ferritin level in our patients was from 182 to $11053 \mathrm{ng} / \mathrm{mL}$ (mean 2067 $\mathrm{ng} / \mathrm{mL}$ ). The mean concentration of sperm was 61.04 million per milliliter. The mean volume of right and left testes was $11.4 \mathrm{cc}$ and $11.7 \mathrm{cc}$, respectively. Those patients who had lower testicular volumes significantly had lower sperm concentration, lower percents of motile and also lower percents of normal morphologic sperms $(\mathrm{P}=0.04)$. The frequency of hypogonadism was significantly higher in patients whose testicular volume was lower $(\mathrm{P}=0.02)$. Hypogonadism and hypothyroidism were seen in $22.6 \%$ and $17.7 \%$ of patients, respectively. Patients with hypogonadism had significantly lower ejaculate volume, lower sperm concentration, lower percents of motile and progressively motile sperms and also lower percents of normal morphologic sperms $(\mathrm{P}=0.001)$. This study suggests that in thalassemic men, concentrations of serum testosterone, LH, FSH has significant correlation with sperm parameters and testicular volume.

\section{Introduction}

$\beta$ thalassemia is a genetic hemoglobinopathy that can result in severe anemia. The life expectancy of these patients has considerably extended by the combination use of transfusion and chelation therapy. ${ }^{1}$ Despite the advances in treatment, endocrinopathies still harms the health of thalassemic patients. In fact, studies have stated that as many as $51 \%$ to $66 \%$ of these patients could have pubertal failure, sexual dysfunction and infertility, due to hypogonadism..$^{2-8}$ The causes of male infertility in general population are multiple, while infertility in $\beta$-thalassemic patients is classically considered to be the result of iron deposition in the endocrine glands. ${ }^{4}$ Adult male patients with $\beta$-thalassemia, on regular blood transfusions, are prone to developing acquired hypogonadism. The frequency of acquired hypogonadism in $\beta$-thalassemia depends mostly on the degree of compliance with blood transfusion and chelation programs. ${ }^{9,10}$ Delay of pubertal sexual maturation in adolescents and decreased libido, erectile dysfunction, and lower quality of life in adults could all be part of clinical manifestations of hypogonadism. In very low levels of gonadotropins and testosterone, spermatogenesis would be impaired, and the volume of ejaculate is decreased. The diagnosis of acquired hypogonadism is confirmed by Low serum concentrations of testosterone and gonadotropins. ${ }^{11-16}$

The aim of this study was to evaluate the fertility indicators including sexual hormone levels, sperm parameters and testicular volume in male patients with $\beta$-thalassemia major and intermedia.

\section{Materials and Methods}

This study was conducted between January 2011 and January 2013 at a teaching hospital in Tehran, Iran. The study included 62 males with $\beta$-thalassemia major and intermedia, whose ages ranged between 18 and 41 years. Among the patients, 52 had been regularly transfused since early childhood and underwent different chelation therapies using subcutaneous desferrioxamine and/or oral deferasirox and/or deferriperone. No participants were on medications known to cause hyperprolactinemia or steroids.

Puberty was evaluated in the patients according to Tanner's classification of testicular development. ${ }^{17}$ Testicular size $<4 \mathrm{~mL}$ (long axis of $\leq 2.5 \mathrm{~cm}$ ) was considered stage I (prepubertal genitalia), and size $>25 \mathrm{~mL}$ ( $\geq 5 \mathrm{~cm}$ in length) was considered adult gen-
Correspondence: Azadeh Kiumarsi, Department of Pediatric Hematology, StAliasghar Hospital, Iran Medical University, Tehran, Iran.

Tel.: +98.2123046411

E-mail: raha1221@yahoo.com

Key words: $\beta$-thalassemia; fertility; spermatogenesis; puberty; hypogonadism; testicular volume.

Received for publication: 26 October 2016. Revision received: 2 July 2017.

Accepted for publication: 5 July 2017.

This work is licensed under a Creative Commons Attribution 4.0 License (by-nc 4.0).

(C) Copyright S. Ansari et al., 2017

Licensee PAGEPress, Italy

Thalassemia Reports 2017; 7:6362

doi:10.4081/thal.2017.6362

italia. Delayed puberty was defined as absence of secondary sexual characteristics with a testicular volume of $<4 \mathrm{~mL}$ at the age of 14 years. ${ }^{18,19}$ By scrotal ultrasound, transverse and longitudinal images of each testis were obtained, and length, width and height measurements were made using electronic calipers. Testicular volume was calculated using the empirical formula of Lambert, length $\times$ width $\times$ height $\times 0.71 .^{20}$

Blood samples were collected from patients for evaluation of their basal $\mathrm{LH}$, FSH, and Testosterone by immunoassay method. In addition, patients were evaluated for thyroid function. Normal serum levels for hormones in our central lab are: Testosterone 2.4-12 ng/mL; LH 1.5-9.3 $\mathrm{mIU} / \mathrm{mL}$; and FSH 1.6-8.0 $\mathrm{mIU} / \mathrm{mL}$ ). Hypogonadism was defined as lower than normal testosterone level.

Semen specimens were collected after an abstinence interval of 3-4 days and they were analyzed according to the World Health Organization guidelines. The following criteria were used to define the semen quality: ${ }^{21-23}$

- The volume of ejaculate less than $1.5 \mathrm{~mL}$ was considered low. Azoospermia was defined as the absence of spermatozoa in patient's ejaculate. Oligospermia was defined as a total number of spermatozoa below the lower reference limit $\left(5^{\text {th }}\right.$ percentile: 15 million $/ \mathrm{mL}$ ).

- Total motile sperm count (class $\mathrm{A}+\mathrm{B}+\mathrm{C}$ ) fewer than $40 \%$ is considered abnormal. The percent of sperms with progressive motility (class A+B) less than $32 \%$ is considered abnormal. The percent of sperms with normal morphology less than $4 \%$ is considered abnormal. 
- Iron overload was assessed by measuring serum ferritin level. Iron status was classified as mild (ferritin $<1000 \mathrm{ng} / \mathrm{mL}$ ), moderate (ferritin $>1000 \mathrm{ng} / \mathrm{mL}$ and $<2500$ $\mathrm{ng} / \mathrm{mL}$ ) or severe (ferritin $>2500 \mathrm{ng} / \mathrm{mL}$ ). ${ }^{24}$ T2* MRI of heart and liver was assessed for iron overload.

\section{Statistical analysis}

Standard computer program SPSS for Windows, release 16.0 was used for data entry and analysis. All numeric variables were expressed as mean \pm standard deviation. Results were analyzed by ANOVA, followed by the independent $t$ test. $\mathrm{P} \leq 0.05$ was considered statistically significant.

The study was approved by the University's Ethical Committee. Patient informed consent was obtained, before beginning the study.

\section{Results}

The patients' age range was between 18 to 41 years. Their mean age was 27.2 years. Considering the thalassemia type, $75.8 \%$ were major and $24.2 \%$ were reported as being intermedia, but at the time of the study $83.9 \%$ were transfusion dependent. Age, type of thalassemia and transfusion dependency did not have significant correlation with hormonal levels, sperm determinants and testicular volumes $(\mathrm{P}>0.05)$.

The mean volume of patients' ejaculate was $2.3 \mathrm{cc}$. Five patients $(8.1 \%)$ had dry ejaculate and $24.2 \%$ of patients had unac- ceptable ejaculate volume $(<1.5 \mathrm{~mL})$. The mean concentration of sperm was 61.04 million per milliliter. Acceptable sperm concentration ( $\geq 15 \mathrm{M} / \mathrm{mL}$ ) was observed in $61.3 \%$ of patients but $21 \%$ had azospermia and $22.4 \%$ had oligospermia.

The number of motile sperms and progressively motile sperms were less than normal in $22.4 \%$ and $34.6 \%$ of patients, respectively. The number of sperms with normal morphology were less than normal in $35.5 \%$ of patients. Normal ejaculate viscosity and $\mathrm{PH}$ was seen in $94.7 \%$ and $91.9 \%$ of patients, respectively. Agglutination in ejaculate sample was only seen in $3.6 \%$ of patients. The characteristics of patients' sperm parameters are summarized in Table 1. The mean volume of right testis was 11.4 $\mathrm{cc}$ and the mean volume of left testis was $11.7 \mathrm{cc}$. Only $3.2 \%$ of patients had testicular volume less than $4 \mathrm{ml}$, which is indicative of the puberty process not being started.
However, those patients who had lower testicular volumes significantly had lower ejaculate volume, lower sperm concentration, lower percents of motile and progressively motile sperms and also lower percents of normal morphologic sperms $(\mathrm{P}=0.04)$. The frequency of hypogonadism was significantly higher in patients whose testicular volume was lower $(\mathrm{P}=0.02)$. The relationship between testicular volume, hypogonadism and sperm parameters are summarized in Table 2.

Varicocele, hydrocele and microlithiasis were seen in $11.3 \%, 1.6 \%$ and $4.8 \%$ of patients, respectively. There was no correlation between having any of the mentioned abnormalities and sperm parameters or with hypogonadism.

Although $17.7 \%$ of patients had hypothyroidism, no significant correlation was found between having hypothyroidism and other evaluated determinants. The mean

Table 1. The characteristics of patients' sperm parameters.

\begin{tabular}{lc}
\hline Number of patients & Sperm parameter \\
$47(75.8 \%)$ & Volume $\geq 1.5 \mathrm{cc}$ \\
$56(90.3 \%)$ & Viscosity $\geq 3.0$ \\
\hline $57(91.9 \%)$ & $\mathrm{PH} \geq 7.2$ \\
$55(96.4 \%)$ & No agglutination \\
\hline $38(61.2 \%)$ & Sperm concentration $>15 \mathrm{M} / \mathrm{mL}$ \\
$38(61.2 \%)$ & Sperm motility $>40 \%$ \\
\hline $32(51.6 \%)$ & Sperm progressive motility $>32 \%$ \\
$40(64.5 \%)$ & Sperm normal morphology $>4 \%$ \\
\hline
\end{tabular}

Table 2. The relationship between testicular volume and hypogonadism and sperm parameters.

\begin{tabular}{lcccccc} 
Testicular volume (Tlanner stage) & $<4$ cc (1) & $4-9$ cc (2) & 10-15 cc (3) & $\mathbf{1 6 - 2 5}$ cc (4) & $>25$ cc (5) & P-value \\
Hypogonadism & 2 & 10 & 2 & 0 & 0 & 0.000 \\
Dry ejaculate & 1 & 4 & 0 & 0 & 0 & 0.010 \\
\hline Low ejaculate volume & 2 & 9 & 4 & 0 & 0 & 0.001 \\
Azospermia & 2 & 9 & 2 & 0 & 0 & 0.000 \\
\hline Oligospermia & 2 & 13 & 7 & 1 & 1 & 0.003 \\
Abnormal sperm motility & 2 & 11 & 8 & 2 & 0 & 0.018 \\
\hline Abnormal sperm morphology & 2 & 10 & 6 & 3 & 1 & 0.035 \\
\hline
\end{tabular}

Table 3. The relationship between hypogonadism and sperm parameters.

\begin{tabular}{|c|c|c|c|c|}
\hline Gonadal status & Normal & Hypogonadotropic hypogonadism & Hypergonadotropic hypogonadism & P-value \\
\hline Dry ejaculate & 2 & 2 & 1 & 0.1 \\
\hline Low ejaculate volume & 7 & 5 & 3 & 0.003 \\
\hline Azospermia & 5 & 6 & 2 & 0.001 \\
\hline Oligospermia & 13 & 8 & 3 & 0.011 \\
\hline Abnormal sperm motility & 11 & 8 & 4 & 0.001 \\
\hline Abnormal sperm morphology & 12 & 7 & 3 & 0.006 \\
\hline
\end{tabular}


level of FSH was $3.7 \mathrm{mIU} / \mathrm{mL}$, LH was 4.6 $\mathrm{mIU} / \mathrm{mL}$, and testosterone was $4.8 \mathrm{ng} / \mathrm{dL}$. The frequency of hypogonadothropic hypogonadism and hypergonadotropic hypogonadism were $16.1 \%$ and $6.5 \%$, respectively. Patients with hypogonadism had significantly lower ejaculate volume, lower sperm concentration, lower percents of motile and progressively motile sperms and also lower percents of normal morphologic sperms $(\mathrm{P}=0.001)$. The relationship between hypogonadism and sperm parameters is summarized in Table 3.

The mean level of serum ferritin was $2067 \mathrm{ng} / \mathrm{dL}$. In $74.2 \%$ of patients cardiac MRI was normal. In $21 \%$ of patients hepatic MRI was normal. Nevertheless, no significant correlation was found between the iron overload determinants and sperm parameters or having hypogonadism.

According to iron chelators, $50 \%$ of patients were using deferoxamine, $50 \%$ of patients were using deferasirox and $21 \%$ of patients were using deferiperrone. Using deferasirox did not have any impact on sperm parameters. On the other hand, in patients who used deferiperrone, oligospermia was significantly more frequent $(\mathrm{P}=0.04)$ and in patients who used deferoxamine, ejaculate volume was significantly lower $(\mathrm{P}=0.006)$. History of using hydroxyurea was documented in $32.3 \%$ of patients, yet using this drug did not have any significant impact on other evaluated parameters.

Finally, $12.9 \%$ of patients had a history of HCV RNA positivity and $48.4 \%$ of patients were splenectomized. Interestingly, $\mathrm{HCV}$ infection did not correlate with sperm parameters but patients who were splenectomized had significantly lower percents of motile and progressively motile sperms and also lower percents of normal morphologic sperms $(\mathrm{P}=0.02)$.

\section{Discussion and Conclusions}

Patients with $\beta$-thalassemia major experience severe anemia and so are dependent on regular blood transfusions, which in turn could lead to iron overload in different organ, particularly the cardiac, hepatic, and endocrine systems. Nevertheless, iron chelation therapy has noticeably improved the prognosis of these patients..$^{25,26}$

The exposure of anterior pituitary to free hydroxyl radicals, especially in early childhood leads to its damage. ${ }^{27}$ Investigators have confirmed by magnetic resonance imaging hat pituitary gland in $\beta$ thalassemic patients with hemochromatosis becomes atrophied ${ }^{28}$ and that serum ferritin level correlates with the severity of pituitary dysfunction. ${ }^{29,30}$ Testicular function is regu- lated by the pulsatile release of $\mathrm{GnRH}$ from the hypothalamus which stimulates the secretion of pituitary gonadotropins and then in the testis, LH mainly stimulates testosterone production and FSH promotes spermatogenesis. ${ }^{31}$

In our study, the correlation between pituitary hormones, testosterone, testicular volume presenting the degree of pubertal development and sperms' count and quality was confirmed. The total prevalence of hypogonadism in our patients was $22.6 \%$, which was near what it was reported by another study in Iran $(22.9 \%))^{32}$

In the study by Soliman et al. testosterone levels were correlated significantly with all the sperm parameters and with $\mathrm{LH}$ levels. ${ }^{28}$ This was also true in our study and patients who had lower levels of serum FSH, LH, and testosterone, had significantly lower ejaculate volume, lower sperm concentration, lower percents of motile and progressively motile sperms and also lower percents of normal morphologic sperms.

De Sanctis et al. showed that FSH, LH and testosterone levels were significantly lower in major thalassemia patients with acquired hypogonadism. ${ }^{10}$ This statement was also true in our study. However, they documented that the percentage of patients with serum ferritin level $>2000 \mathrm{ng} / \mathrm{mL}$ (severe iron load) was significantly higher in patients with acquired hypogonadism. In our study, level of serum ferritin at the time of study did not correlate with FSH, LH, testosterone and sperm parameters. This is not a reliable conclusion because unfortunately we could not track their ferritin levels in the past. However, the severity of iron overload in heart and liver MRI of our patients, which are a more chronic representatives of iron burden, did not correlate with FSH, LH, testosterone and sperm parameters either. It has been demonstrated in different studies that the damage caused by iron overload to the gonads is an irreversible process, even if the iron level is corrected at a later stage. ${ }^{27,30,33}$ This affirms the significance of early and regular usage of iron chelation therapy in order to prevent the onset of damage to the pituitary gland and the gonads. ElAlfy et al. documented that combination chelation using deferiprone and desferrioxamine in transfusion dependant thalassemic males with good pituitary-testicular function led to progression of pubertal development but it did not improve their semen quality. ${ }^{34}$ In our study, interestingly, iron chelator usage did not correlate with better sperm quality but in fact, the patients who used deferiprone and/or desferrioxamine had significantly lower ejaculate volume and also utilization of deferiprone was associated with having oligospermia. ${ }^{5}$ Karimi et al. declared that long-term use of hydroxyurea has no effect on gonad function in $\beta$-talassemia patients. ${ }^{35}$ In our study as well, the history of hydroxyurea usage did not affect hormonal status or the sperm parameters.

The limitations of this study were as follows: Albumin and SHBG which could change the bioavailability of testosterone were not measured. Patients who had varicocele were not excluded from the study. For azoospermic patients, a karyotype or $\mathrm{Y}$ microdeletion assay were not performed to rule out alternative causes for poor semen parameters and smaller testicular size. Only one semen analysis was done for each subject, which is not adequate to overcome the significant variability of this test. The duration of each chelator's usage and the duration of hydroxyurea usage were not documented.

In conclusion, we found that there was a significant relationship between hypogonadism and sperm parameters, which could both affect our patients' fertility potential. As fatherhood is indubitably one of the main factors, which could improve the thalassemic patients' quality of life, therefore, the issue of male fertility and its affectors should be considered in mind.

\section{References}

1. Borgna-Pignatti CA, Rugolotto SI, De Stefano P, et al. Survival and complications in patients with thalassemia major treated with transfusion and deferoxamine. Haematologica 2004;89:1187-93.

2. Galanello R, Origa R. $\beta$-thalassemia. Orphanet J Rare Dis 2010;5:11.

3. De Sanctis V, Elawwa A, Angastiniotis M, et al. Highlights from the First Thalassaemia forum on growth and endocrine complications in thalassemia Doha (October 2-3, 2011). Pediatr Endocrinol Rev 2012;9:672-9.

4. De Sanctis V, Giovannini M. Endocrine histology findings in a prepubertal thalassemic girl with multiple endocrine complications secondary to iron overload. Georgian Med News 2011; 193:51-5.

5. Ares-Serono Foundation. Proceedings of the Ares-Serono Foundation 2nd International Workshop on growth and endocrine complications and reproduction in thalassaemia. Ferrara, Italy. April 2-4, 1998. J Pediatr Endocrinol Metab 1998;11:771-1008.

6. Soliman A, Yasin M, El-Awwa A, et al. Acute effects of blood transfusion on pituitary gonadal axis and sperm parameters in adolescents and young men 
with thalassemia major: a pilot study. Fertil Steril 2012;98:638-43.

7. Roth C, Pekrun A, Bartz M, et al. Short stature and failure of pubertal development in thalassaemia major: evidence for hypothalamic neurosecretory dysfunction of growth hormone secretion and defective pituitary gonadotropin secretion. Eur J Pediatr 1997;156:777.

8. Valenti S, Giusti M, McGuinness D, et al. Delayed puberty in males with $\beta$-thalassemia major: pulsatile gonadotropinreleasing hormone administration induces changes in gonadotropin isoform profiles and an increase in sex steroids. Eur J Endocrinol 1995;133:48.

9. De Sanctis V, D'Ascola G, Wonke B.

The development of diabetes mellitus and chronic liver disease in long term chelated $\beta$ thalassaemic patients. Postgrad Med J 1986;62:831-6.

10. De Sanctis V, Elsedfy H, Soliman AT, et al. Acquired hypogonadotropic hypogonadism (AHH) in thalassaemia major patients: an underdiagnosed condition? Mediterr J Hematol Infect Dis 2016;8:e2016001.

11. Silveira LF, MacColl GS, Bouloux PM. Hypogonadotropic hypogonadism. Semin Reprod Med 2002;20:327-38.

12. Fraietta R, Zylberstejn DS, Esteves SC. Hypogonadotropic hypogonadism revisited. Clinics (Sao Paulo) 2013; 68:81-8

13. Naghtigall LB, Boepple PA, Pralong FP, Crowley WF Jr. Adult onset idiopathic hypogonadotropic hypogonadism: a treatable form of male infertility. N Engl J Med 1997;336:410-5.

14. Tash JA, McGovern JH, Schlegel PN. Acquired hypogonadotropic hypogonadism presenting as decreased seminal volume. Urology 2000;56:669.

15. Dwyer AA, Raivio T, Pitteloud N. Gonadotrophin replacement for induction of fertility in hypogonadal men. Best Pract Res Clin Endocrinol Metab 2015;29:91-103.

16. Salenave S, Trabado S, Maione L, et al. Male acquired hypogonadotropic hypogonadism: diagnosis and treatment. Ann Endocrinol (Paris)
2012;73:141-6.

17. Tanner JM, Whithehouse RH. Clinical longitudinal standards for height, weight, height velocity, weight velocity, and the stages of puberty. Arch Dis Child 1976;51:170-9.

18. Italian Working Group on Endocrine Complications in Nonendocrine Diseases. Multicentre study on prevalence of endocrine complications in thalassaemia major. Clin Endocrinol 1995;42:581-6.

19. Kauschansky A, Dickerman Z, Phillip $\mathrm{M}$, et al. Use of GnRH agonist and human chorionic gonadotrophin tests for differentiating constitutional delayed puberty from gonadotrophin deficiency in boys. Clin Endocrinol 2002;56:603-7.

20. Hsieh ML, Huang ST, Huang HC, et al. The reliability of ultrasonographic measurements for testicular volume assessment: comparison of three common formulas with true testicular volume. Asian J Androl 2009;11:261.

21. Borgna-Pignatti C. The life of patients with thalassemia major. Haematologica 2010;95:3458.

22. Tanner JM. Growth at adolescence. Springfield, IL: Charles C. Thomas; 1962.

23. World Health Organisation. Laboratory manual for the examination and processing of human semen. 5th ed. Geneva: World Health Organization; 2010.

24. Casale M, Meloni A, Filosa A, et al. Multiparametric cardiac magnetic resonance survey in children with thalassemia major: a multicenter study. Circ Cardiovasc Imaging 2015;8: e003230.

25. Maggio A, Vitrano A, Capra M, et al. Improving survival with deferiprone treatment in patients with thalassemia major: a prospective multicenter randomised clinical trial under the auspices of the Italian Society for Thalassemia and Hemoglobinopathies. Blood Cells Mol Dis 2009;42:247-51.

26. Telfer P, Coen PG, Christou S, et al. Survival of medically treated tha- lassemia patients in Cyprus. Trends and risk factors over the period 1980-2004. Haematologica 2006;91:1187-92.

27. De Sanctis V, Wonke B. Growth and endocrine complication in thalassaemia. Roma: Mediprint; 1998. pp 17-30.

28. Soliman AT, El Zalabany M, Ragab M, et al. Spontaneous and GnRH-provoked gonadotropin secretion and human chorionic gonadotropin in adolescent boys with thalassaemia major and delayed puberty. J Trop Pediatr 2000;46:79-85.

29. Sparacia G, Iaia A, Banco A, et al. Transfusional hemochromatosis: quantitative relation of MR imaging pituitary signal intensity reduction to hypogonadotropic hypogonadism. Radiology 2000;215:818-23.

30. De Sanctis V. Growth and puberty and its management in thalassaemia. Horm Res 2002;58:72-9.

31. Amory JK, Bremner W. Endocrine regulation of testicular function in men: implications for contraceptive development. Mol Cell Endocrinol 2001;182:175-9.

32. Shamshirsaz AA, Bekheirnia MR, Kamgar M, et al. Metabolic and endocrinologic complications in $\beta$-thalassemia major: a multicenter study in Tehran. BMC Endocr Disord 2003;3:4.

33. Chatterjee R, Katz M. Reversible hypogonadotrophic hypogonadism in sexually infantile male thalassaemic patients with transfusional iron overload. Clin Endocrinol 2000;53:33- 42.

34. ElAlfy M, Ragab E, Abdel-Aziz E, et al. Deferiprone and desferrioxamine combined chelation could improve puberty of adolescent males with $\beta$-thalassemia major with preserved pituitary and testicular function. Egypt $\mathrm{J}$ Haematol 2013;38:4.

35. Karimi M, Zekavat OR, Haghpanah S, Javad P, Karamizadeh Z. Comparative study of hypogonadism in $\beta$-thalassemia intermedia patients with and without hydroxyurea. Hematology 2012;17:2. 